\title{
Strategi Pengembangan Penangkapan Ikan Pelagis Kecil dengan Alat Tangkap Jaring Insang di Kabupaten Maluku Tenggara (The Development Strategy of Catching the Small Pelagic Fish by Gill Net Fishing Gear in Southeast Maluku Regency)
}

\author{
Elisabeth Cory Ohoiwutun \\ Politeknik Perikanan Negeri Tual \\ Jln. Raya Langgur - Sathean Km. 6 Kabupaten Maluku Tenggara \\ e-mail: elisabeth c ohoiwutun@yahoo.com
}

Diterima/disetujui : 18 Juni 2015/ 25 Juni 2015

\begin{abstract}
The regency of southeast Maluku has a variety of promising fisheries and marine potency to be managed. Unfortunately, it has not been used properly. The fishing production volume of small pelagic in every season using gill net fishing gear has not been able to increase the income of fishermen in Southeast Maluku regency. The analytical methods used were the External Factor Evaluation (EFE), Internal Factor Evaluation (IFE), Internal-External (IE) and Strengths Weaknesses Opportunities Threats (SWOT) analytical matrix. These were used to develop the strategy of small Pelagic with gill net fishing gear. Based on the result, gill net fishing gear has a number of different production each season against every kind of small pelagic fish.
\end{abstract}

Keywords: fishermen, gillnet,sSmall pelagic fish

\section{PENDAHULUAN}

Pemanfataan sumberdaya perikanan laut di masa mendatang dihadapkan pada kenyataan bahwa hingga saat ini sebagian besar sumberdaya perikanan dimanfaatkan oleh perikanan berskala kecil atau perikanan rakyat. Keadaan usaha perikanan rakyat pada umumnya masih tradisional dan jangkauan daerah penangkapan yang terbatas di perairan pantai sehingga produktivitas yang dihasilkan masih rendah (Bahari 1989). Menurut Barus et al. (1991) produktivitas nelayan yang masih rendah pada umumnya diakibatkan oleh rendahnya keterampilan dan pengetahuan serta penggunaan alat penangkapan dan perahu yang masih sederhana, sehingga efektivitas dan efesiensi alat tangkap maupun perahu belum optimal. Keadaan ini berpengaruh terhadap pendapatan yang diterima nelayan yang relatif rendah, sehingga keadaan ekonomi dan kesejahteraan nelayan pada umumnya masih tertinggal bila dibandingkan dengan masyarakat petani atau masyarakat lainnya.

Salah satu yang harus disikapi oleh pemerintah demi tercapainya keberhasilan pembangunan perikanan adalah kebijakan Pemerintah Daerah (Pemda). Hingga saat ini masih banyak Pemda yang belum menunjukkan keberpihakan terhadap pembangunan wilayah pesisir dan laut, khususnya pada pengentasan kemiskinan masyarakat nelayan sebagai pelaku utama usaha perikanan yang menjadi sumber masalah dasar pembangunan perikanan (Solihin 2010).

Kabupaten Maluku Tenggara memiliki pulau-pulau kecil yang membentang, membentuk perairan dangkal yang mengandung aneka biota ekonomis penting yang memiliki nilai jual tinggi, sehingga sangat potensial sebagai daerah penangkapan ikan, termasuk ikan pelagis kecil. Usaha perikanan yang berkembang di Kabupaten Maluku Tenggara masih tergolong perikanan pantai dimana kegiatan penangkapan dilakukan oleh 
perikanan rakyat. Tingkat pemanfaatan yang belum optimal ini diduga disebabkan karena masih rendahnya produktivitas usaha penangkapan karena menggunakan alat tangkap yang sederhana dan armada penangkapan yang kecil.

Jenis ikan pelagis kecil yang ditangkap menggunakan jaring insang di Kabupaten Maluku Tenggara terdiri dari ikan kembung, selar, layang dan lemuru. Jenis armada penangkapan yang digunakan nelayan terdiri dari perahu tanpa motor, motor tempel dan kapal motor. Jenis armada lebih didominasi oleh perahu tanpa motor, dimana pada tahun 2011 jumlahnya mencapai 12.601 unit (DKP Kabupaten Maluku Tenggara 2012).

Dengan gambaran kondisi perikanan seperti diuraikan diatas dapat dikatakan bahwa kegiatan perikanan tangkap di daerah ini masih bersifat sederhana karena terbatasnya sarana penangkapan ikan. Oleh karena itu peneliti tertarik untuk melakukan penelitian dengan judul Strategi Pengembangan Penangkapan Ikan Pelagis Kecil di Kabupaten Maluku Tenggara dengan Alat Tangkap Jaring Insang. Penelitian ini dilakukan dengan tujuan untuk menganalisis faktor internal dan eksternal, serta strategi pengembangan perikanan pelagis kecil dengan alat tangkap jaring insang.

\section{Lokasi Penelitian}

\section{METODOLOGI}

Penelitian ini dilakukan di Kabupaten Maluku Tenggara dikhususkan pada Desadesa nelayan yang terdapat di Kabupaten Maluku Tenggara.

\section{Jenis dan Sumber Data}

Data yang digunakan dalam penelitian ini adalah data primer dan sekunder. Data primer didapatkan langsung melalui wawancara dengan alat bantu kuesioner terhadap pihak-pihak yang terlibat dalam strategi pengembangan penangkapan ikan Pelagis kecil, yaitu nelayan dan instansi yang terkait dengan obyek penelitian. Data sekunder diperoleh dengan cara melakukan studi pustaka pada disertasi, tesis, jurnal ilmiah, internet dan menggunakan informasi-informasi yang dihasilkan oleh instansi terkait dengan obyek penelitian.

\section{Teknik Pengumpulan Data}

Pengumpulan data dilakukan melalui tiga cara, yaitu (1) Survei langsung lapangan, yaitu melihat dan mempelajari keadaan usaha penangkapan ikan pelagis kecil dengan alat tangkap jaring insang, mempelajari saluran distribusi yang dilakukan dan semua aspek pendukung; (2) Wawancara dengan pihak-pihak yang terlibat dalam strategi pengembangan penangkapan ikan pelagis kecil; dan (3) Opini pakar yang diperoleh dari pakar-pakar yang terkait dengan topik penelitian.

Penentuan responden dalam penelitian ini dilakukan menggunakan purposive sampling dengan persyaratan bahwa responden merupakan pelaku (baik individu atau lembaga) yang memengaruhi pengambilan kebijakan, baik langsung maupun tak langsung, dalam strategi pengembangan penangkapan ikan pelagis kecil di Kabupaten Maluku Tenggara.

Pengambilan data sekunder dilakukan dari berbagai sumber seperti Dinas Kelautan dan Perikanan, perpustakaan daerah dan lain-lain. Data yang diambil diantaranya data perkembangan lima tahun terakhir jenis alat tangkap dan armada penangkapan. 


\section{Teknik Pengolahan dan Analisis Data}

Pengolahan data dilakukan dengan menganalisis strategi pengembangan penangkapan ikan pelagis kecil melalui tahapan, yaitu (a) Analisis perumusan strategi : (1) Analisis Matriks IFE-EFE; (2). Analisis Matriks IE dan (3) Analisis Matriks SWOT.

\section{Analisis Faktor Internal dan Eksternal (IFE - EFE)}

Analisis eksternal dilakukan untuk mengembangkan daftar yang terbatas tentang peluang yang dapat memberi manfaat dan ancaman yang harus dihindari dalam pengembangan kebijakan perikanan jaring insang di lokasi kajian. (David, 2006).

Analisis internal dilakukan untuk mengidentifikasi kekuatan dan kelemahan dalam rangka pengembangan kebijakan perikanan jaring insang di lokasi kajian. Analisis internal sangat berkaitan erat dengan sumber daya yang dimiliki (David 2006).

\section{Matriks IE}

Penyusunan matriks IE dalam kajian ini akan dibagi menjadi tiga bagian, yaitu:

1) Divisi yang berada pada sel I, II dan IV menunjukkan strategi pengembangan dan membangun (Growth and Build).

2) Divisi yang berada pada sel III, V dan VII ditujukan untuk melaksanakan strategi mempertahankan dan memelihara (Hold and Maintain).

3) Divisi yang berada pada sel VI, VIII, dan IX menunjukkan strategi mengambil hasil atau melepaskan (Harvest or Divest).

\section{Matriks SWOT}

Matriks SWOT mengembangkan empat tipe strategi (David 2006). Matriks SWOT serta keempat strategi yang dapat dikembangkan disajikan pada Tabel 1.

Tabel 1 Model Matriks Analisis SWOT

\begin{tabular}{|c|c|c|}
\hline EFE IFE & $\begin{array}{l}\text { STRENGHT }(S) \\
\text { Tentukan faktor-faktor } \\
\text { kekuatan internal }\end{array}$ & $\begin{array}{l}\text { WEAKNESSES }(W) \\
\text { Tentukan faktor-faktor } \\
\text { kelemahan internal } \\
\end{array}$ \\
\hline $\begin{array}{l}\text { OPPORTUNITIES }(O) \\
\text { Tentukan faktor } \\
\text { peluang eksternal }\end{array}$ & $\begin{array}{l}\text { STRATEGI (SO) } \\
\text { Menciptakan strategi } \\
\text { menggunakan kekuatan } \\
\text { untuk mendapatkan } \\
\text { peluang }\end{array}$ & $\begin{array}{l}\text { STRATEGI (WO) } \\
\text { Menciptakan strategi } \\
\text { yang mengurangi } \\
\text { kelemahan untuk } \\
\text { memanfaatkan pluang }\end{array}$ \\
\hline $\begin{array}{l}\text { THREATS }(T) \\
\text { Tentukan faktor ancaman } \\
\text { Eksternal }\end{array}$ & $\begin{array}{l}\text { STRATEGI (ST) } \\
\text { Menciptakan strategi } \\
\text { yang menggunakan } \\
\text { kekuatan untuk } \\
\text { mengatasi ancaman }\end{array}$ & $\begin{array}{l}\text { STRATEGI (WT) } \\
\text { Menciptakan strategi } \\
\text { yang meminimalkan } \\
\text { kelemahan dan } \\
\text { menghindari ancaman }\end{array}$ \\
\hline
\end{tabular}

\section{HASIL DAN PEMBAHASAN}

\section{Unit Penangkapan}

Unit penangkapan yang produktif menangkap jenis ikan pelagis kecil di perairan Kabupaten Maluku Tenggara yaitu jaring insang (gillnet). Perkembangan jenis dan jumlah alat tangkap jaring insang yang beroperasi di Kabupaten Maluku Tenggara dapat dilihat pada Tabel 2. 
Tabel 2 Perkembangan jumlah alat tangkap jaring insang di Kabupaten Maluku Tenggara tahun 2007 - 2011 (dalam unit)

\begin{tabular}{cc}
\hline Tahun & Jaring Insang \\
\hline 2007 & 3157 \\
2008 & 2649 \\
2009 & 2700 \\
2010 & 2604 \\
2011 & 2760
\end{tabular}

Sumber: DKP Kab. Maluku Tenggara, (2012)

Jenis ikan Pelagis kecil yang ditangkap nelayan di Kabupaten Maluku Tenggara dengan menggunakan jaring insang terdiri dari ikan kembung, ikan selar, ikan layang dan ikan lemuru. Penangkapan ikan pelagis kecil yang dilakukan dengan menggunakan jenis alat tangkap jaring insang umumnya menggunakan perahu tanpa motor dan ketinting dengan merk mesin Honda dan mempunyai kekuatan 5.5 PK.

Ukuran mata jaring yang digunakan yaitu $3.9-4.8 \mathrm{~cm}$. Panjang bagian pelampung $50 \mathrm{~m}$ dan panjang bagian pemberat $52 \mathrm{~m}$. Pada saat operasi penangkapan, setelah dilakukan pengaturan, jaring dibiarkan selama 3 - 4 jam dan selanjutnya dilakukan penarikan jaring (Martasuganda 2008). Kapal penangkapan yang digunakan oleh masyarakat nelayan sampai tahun 2011 masih didominasi oleh perahu tanpa motor. Jumlah kapal atau perahu yang beroperasi di Kabupaten Maluku Tenggara dapat dilihat pada Tabel 3 .

Tabel 3 Perkembangan jumlah kapal/perahu nelayan di Kabupaten Maluku Tenggara tahun 2007-2011 (dalam unit)

\begin{tabular}{ccc}
\hline Tahun & Perahu Tanpa Motor & Motor Tempel \\
\hline 2007 & 5284 & 894 \\
2008 & 4032 & 704 \\
2009 & 3792 & 727 \\
2010 & 10020 & 9102 \\
2011 & 12601 & 1034 \\
\hline
\end{tabular}

Sumber: DKP Kab. Maluku Tenggara, (2012)

\section{Hasil Tangkapan Ikan Pelagis Kecil}

Jenis ikan pelagis kecil yang dominan terdiri dari ikan kembung, selar, layang dan lemuru. Perkembangan produksi perikanan tangkap ikan Pelagis kecil berdasarkan jenis ikan untuk setiap musim pada satu tahun dan berdasarkan jenis alat tangkap jaring insang dapat dilihat pada Tabel 4.

Tabel 4 Produksi alat tangkap jaring insang pada satu tahun menurut jenis ikan pelagis kecil dan berdasarkan musim

\begin{tabular}{|c|c|c|c|c|c|}
\hline \multirow{2}{*}{$\begin{array}{l}\text { Jenis Ikan } \\
(\mathrm{kg})\end{array}$} & \multicolumn{4}{|c|}{ Musim } & \multirow{2}{*}{$\begin{array}{c}\text { Total } \\
(\mathrm{kg})\end{array}$} \\
\hline & Barat & Pancaroba 1 & Timur & Pancaroba 2 & \\
\hline Kembung & 1890 & 3780 & 10080 & 3780 & 19530 \\
\hline Teri & - & - & - & - & - \\
\hline Selar & 1890 & 3780 & 10080 & 3780 & 19530 \\
\hline Layang & 3780 & 5040 & 12600 & 5670 & 27090 \\
\hline Lemuru & - & 3780 & 10080 & 3780 & 17640 \\
\hline Total & 7560 & 16380 & 42840 & 17010 & 83790 \\
\hline
\end{tabular}


Tabel 4 memperlihatkan perkembangan jumlah produksi alat tangkap jaring insang menurut jenis ikan pelagis kecil dan musim penangkapan. Alat tangkap jaring insang memiliki jumlah produksi berbeda pada setiap musim terhadap setiap jenis ikan pelagis kecil. Kondisi demikian disebabkan karena jenis alat tangkap jaring insang, ada yang tidak dapat menangkap ikan pelagis kecil yaitu ikan teri pada setiap musim dan ikan lemuru pada musim barat. Hasil penelitian ini didukung oleh Hobday (2010) yang menyatakan bahwa iklim sangat memengaruhi jumlah hasil tangkapan.

\section{Analisis Faktor Internal}

Analisis faktor internal terdiri dari faktor-faktor kekuatan dan kelemahan. Faktor kekuatan penangkapan ikan pelagis kecil terdiri dari tiga faktor dan faktor kelemahan penangkapan ikan pelagis kecil terdiri dari enam faktor. Faktor-faktor kekuatan dan kelemahan tersebut diuraikan dibawah ini.

\section{a. Kekuatan :}

1) Semangat kerja nelayan yang tinggi

2) Kegigihan nelayan dalam menghadapi kesulitan dalam pekerjaannya

3) Nelayan memiliki pengalaman yang baik pada usaha penangkapan ikan

b. Kelemahan :

1) Keterampilan dan penguasaan teknologi masih kurang

2) Tingkat pendidikan nelayan rendah

3) Keterbatasan alat tangkap dan armada penangkapan ikan

4) Keterbatasan modal nelayan

5) Posisi tawar nelayan dalam pemasaran rendah

6) Belum adanya pembukuan keuangan usaha yang baik

\section{Analisis Faktor Eksternal}

Analisis faktor eksternal terdiri dari faktor-faktor peluang dan ancaman. Faktor peluang yang dimiliki oleh nelayan di Kabupaten Maluku Tenggara terdiri dari empat faktor dan faktor ancaman terdiri dari lima faktor. Faktor-faktor peluang dan ancaman tersebut diuraikan dibawah ini.

\section{a. Peluang}

1) Lokasi penangkapan luas

2) Mutu perairan yang cukup baik

3) Potensi sumber daya perikanan tangkap yang besar

4) Program pemerintah yang mendukung pengembangan usaha

\section{b. Ancaman :}

1) Kerusakan ekosistem laut akibat penangkapan destruktif

2) Harga BBM tinggi

3) Hasil produksi berfluktuasi

4) Harga pasar ditentukan oleh pihak pengumpul

5) Perbatasan di wilayah laut

\section{Analisis Matriks IFE}

Faktor-faktor yang menyusun matriks IFE adalah faktor-faktor internal yang terdiri dari kekuatan dan kelemahan. Hasil analisis matriks IFE dapat dilihat pada Tabel 5. 
Tabel 5 Hasil Analisis Matriks IFE

\begin{tabular}{|c|c|c|c|}
\hline Faktor Internal & $\begin{array}{l}\text { Bobot } \\
\text { (A) }\end{array}$ & $\begin{array}{l}\text { Rating } \\
\text { (B) }\end{array}$ & $\begin{array}{l}\text { Skor } \\
(\mathbf{A x B})\end{array}$ \\
\hline \multicolumn{4}{|l|}{ KEKUATAN } \\
\hline Semangat kerja nelayan yang tinggi & 0.143 & 4.0 & 0.572 \\
\hline $\begin{array}{l}\text { Kegigihan nelayan dalam menghadapi kesulitan } \\
\text { dalam pekerjaannya }\end{array}$ & 0.131 & 3.8 & 0.498 \\
\hline $\begin{array}{l}\text { Nelayan memiliki pengalaman yang baik pada } \\
\text { usaha penangkapan ikan }\end{array}$ & 0.126 & 3.8 & 0.479 \\
\hline \multicolumn{4}{|l|}{ KELEMAHAN } \\
\hline Tingkat pendidikan nelayan rendah & 0.103 & 1.8 & 0.185 \\
\hline $\begin{array}{l}\text { Keterampilan dan penguasaan teknologi masih } \\
\text { kurang }\end{array}$ & 0.093 & 1.8 & 0.168 \\
\hline Posisi tawar nelayan dalam pemasaran rendah & 0.090 & 1.8 & 0.162 \\
\hline $\begin{array}{l}\text { Belum adanya pembukuan keuangan usaha yang } \\
\text { baik }\end{array}$ & 0.096 & 1.6 & 0.154 \\
\hline $\begin{array}{l}\text { Keterbatasan alat tangkap dan armada penangkapan } \\
\text { ikan }\end{array}$ & 0.110 & 1.0 & 0.110 \\
\hline Keterbatasan modal nelayan & 0.108 & 1.0 & 0.108 \\
\hline TOTAL & 1.000 & 20.6 & 2.435 \\
\hline
\end{tabular}

Berdasarkan hasil perhitungan matriks IFE pada Tabel 5 dapat dilihat bahwa faktor kekuatan yang menduduki peringkat pertama dengan nilai tertimbang 0.572 adalah semangat kerja nelayan tinggi. Faktor ini menjadi salah satu kekuatan yang sangat penting dalam pengembangan penangkapan ikan Pelagis kecil di Kabupaten Maluku Tenggara.

Pada faktor kelemahan, tingkat pendidikan nelayan rendah memiliki nilai tertimbang tertinggi, yaitu 0.185 . Tingkat pendidikan nelayan yang rendah sangat mempengaruhi pengembangan usaha perikanan. Untuk itu perumusan strategi yang akan dilaksanakan dalam pengembangan penangkapan ikan pelagis kecil perlu mempertimbangkan faktor ini agar dapat berjalan sesuai dengan apa yang diinginkan.

Bobot skor total diperoleh adalah 2.435. Hal ini menunjukkan bahwa strategi pengembangan penangkapan ikan pelagis kecil di Kabupaten Maluku Tenggara memiliki posisi internal yang sedang, dalam artian bahwa strategi pengembangan penangkapan ikan pelagis kecil memiliki peluang untuk berkembang dengan baik, namun belum secara optimal menggunakan kekuatan yang dimiliki dan mengatasi kelemahan.

\section{Analisis Matriks EFE}

Matriks EFE berguna untuk mengetahui seberapa besar faktor-faktor eksternal yang memengaruhi strategi pengembangan penangkapan ikan pelagis kecil di Kabupaten Maluku Tenggara. Faktor eksternal terdiri dari peluang dan ancaman. Hasil analisis matriks EFE dapat dilihat pada Tabel 6.

Berdasarkan hasil perhitungan matriks EFE pada Tabel 6 dapat dilihat bahwa faktor peluang yang menduduki peringkat pertama dengan nilai tertimbang 0.589 yaitu potensi sumber daya perikanan tangkap yang besar. Faktor ini menjadi salah satu peluang yang sangat penting dalam kelayakan dan strategi pengembangan penangkapan ikan pelagis kecil di Kabupaten Maluku Tenggara. Hal ini juga didukung oleh faktor-faktor peluang lainnya yang merupakan peluang cukup penting untuk diperhatikan. 
Tabel 6 Hasil Analisis Matriks EFE

\begin{tabular}{lccc}
\hline \multicolumn{1}{c}{ Faktor Eksternal } & $\begin{array}{c}\text { Bobot } \\
(\mathbf{A})\end{array}$ & $\begin{array}{c}\text { Rating } \\
(\mathbf{B})\end{array}$ & $\begin{array}{c}\text { Skor } \\
(\mathbf{A x B})\end{array}$ \\
\hline PELUANG & & & \\
Potensi sumber daya perikanan tangkap yang besar & $\mathbf{0 . 1 4 7}$ & $\mathbf{4 . 0}$ & $\mathbf{0 . 5 8 9}$ \\
Lokasi penangkapan luas & 0.132 & 4.0 & 0.527 \\
Mutu perairan cukup baik & 0.119 & 4.0 & 0.478 \\
Program pemerintah yang mendukung pengembangan & 0.078 & 3.2 & 0.248 \\
usaha penangkapan & & & \\
ANCAMAN & & & \\
Hasil produksi berfluktuasi & $\mathbf{0 . 1 4 3}$ & $\mathbf{2 . 0}$ & $\mathbf{0 . 2 8 5}$ \\
Harga BBM tinggi & 0.110 & 2.0 & 0.220 \\
Kerusakan ekosistem laut akibat penangkapan & 0.098 & 2.0 & 0.195 \\
destruktif & & & \\
Perbatasan di wilayah laut & 0.099 & 1.0 & 0.099 \\
Harga pasar ditentukan oleh pihak pengumpul & 0.074 & 1.0 & 0.074 \\
\hline \multicolumn{1}{c}{ TOTAL } & $\mathbf{1 . 0 0 0}$ & $\mathbf{2 2 . 8}$ & $\mathbf{2 . 7 1 6}$ \\
\hline
\end{tabular}

Pada faktor ancaman hasil produksi berfluktuasi memiliki nilai tertimbang tertinggi yaitu 0.285 dan menjadi ancaman besar bagi nelayan di Kabupaten Maluku Tenggara. Ancaman ini dapat mengganggu usaha perikanan bagi nelayan karena secara langsung memengaruhi pendapatan nelayan. Hal ini menunjukkan bahwa faktor ini diharapkan segera dapat diatasi dan diharapkan adanya suatu strategi yang akan dilaksanakan untuk dapat segera mengatasi masalah tersebut. Bobot skor total pada faktor eksternal 2.716. Hal ini menunjukkan bahwa strategi pengembangan penangkapan ikan pelagis kecil memiliki posisi eksternal yang sedang, artinya bahwa strategi pengembangan penangkapan ikan pelagis kecil di daerah ini memiliki kemampuan merespon tergolong sedang dan belum menggunakan secara optimal peluang-peluang yang ada untuk mengatasi ancaman.

\section{Analisis Matriks IE}

Matriks IE merupakan matriks yang menggabungkan bobot skor pada Matriks IFE dan Matriks EFE untuk melihat posisi sel strategi pengembangan penangkapan ikan pelagis kecil di Kabupaten Maluku Tenggara. Dari perhitungan Matriks IFE didapatkan bobot skor 2,435 dan Matriks EFE didapatkan bobot skor 2,716. Hasil pemetaan Matriks IE dapat dilihat pada Gambar 2.

Strategi pengembangan penangkapan ikan pelagis kecil di Kabupaten Maluku Tenggara menempati posisi sel V. Sel V ini menggambarkan bahwa posisi strategi pengembangan penangkapan ikan pelagis kecil berada pada posisi menjaga dan mempertahankan. Strategi yang tepat bagi usaha yang berada di sel ini yaitu strategi penetrasi pasar dan strategi pengembangan produk (David 2006). 


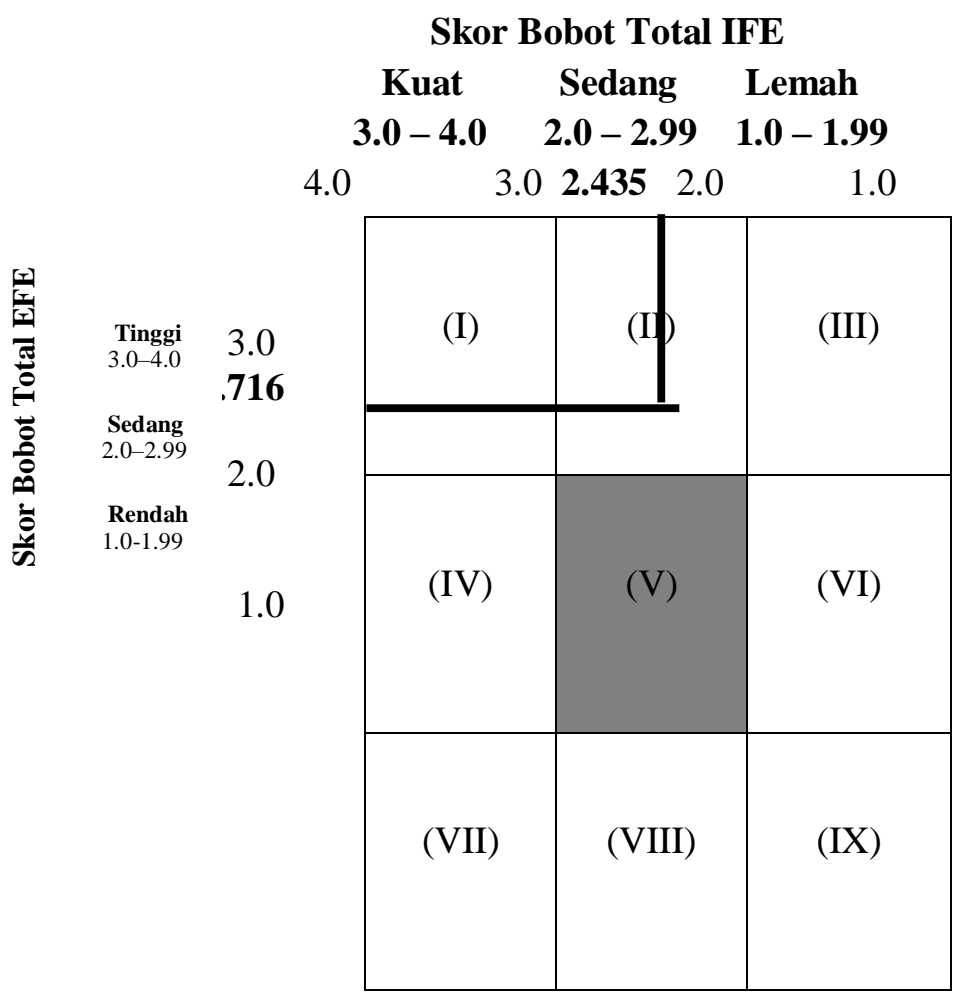

Gambar 2 Hasil Matriks IE

\section{Analisis Matriks SWOT}

Perumusan strategi pengembangan penangkapan ikan pelagis kecil di Kabupaten Maluku Tenggara dimuat pada Tabel 7. Perumusan strategi dengan matriks SWOT terdiri dari empat (4) kombinasi faktor, yang terdiri dari strategi Kekuatan-Peluang (S-O), strategi Kekuatan-Ancaman (S-T), strategi Kelemahan-Peluang (W-O) dan strategi Kelemahan-Ancaman (W-T).

Berdasarkan Tabel 7 terdapat delapan strategi yang dapat dirumuskan dari kombinasi faktor internal dan eksternal. Delapan strategi tersebut dapat digunakan pada strategi pengembangan penangkapan ikan pelagis kecil di Kabupaten Maluku Tenggara. 
Tabel 7 Matriks SWOT strategi pengembangan penangkapan ikan pelagis kecil di Kabupaten Maluku Tenggara

\begin{tabular}{|c|c|c|}
\hline Faktor-faktor & Kekuatan (Strenghts-S) & Kelemahan (Weakness-W) \\
\hline Faktor Internal & $\begin{array}{ll}\text { 1. } & \text { Semangat kerja nelayan yang } \\
\text { tinggi (S1) } \\
\text { 2. Kegigihan nelayan dalam } \\
\text { menghadapi kesulitan dalam } \\
\text { pekerjaannya (S2) } \\
\text { 3. Nelayan memiliki } \\
\text { pengalaman yang baik pada } \\
\text { usaha penangkapan ikan (S3) }\end{array}$ & 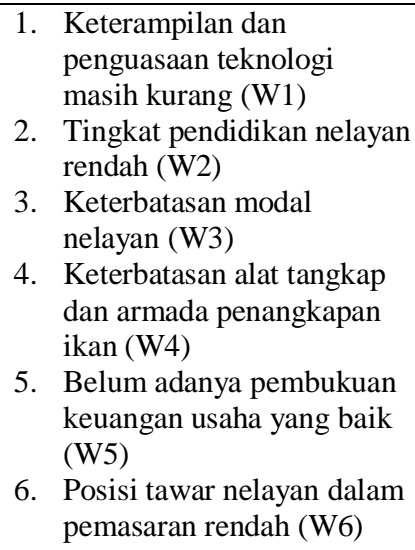 \\
\hline Peluang (Opportunities-O) & Strategi S-O & Strategi W-O \\
\hline $\begin{array}{l}\text { 1. Lokasi penangkapan luas } \\
\text { (O1) } \\
\text { 2. Mutu perairan yang cukup } \\
\text { baik }(\mathrm{O} 2) \\
\text { 3. Potensi sumber daya } \\
\text { perikanan tangkap yang } \\
\text { besar }(\mathrm{O} 3) \\
\text { 4. Program pemerintah yang } \\
\text { mendukung pengembangan } \\
\text { usaha penangkapan }(\mathrm{O} 4)\end{array}$ & $\begin{array}{l}\text { 1. Meningkatkan semangat } \\
\text { kerja nelayan dengan } \\
\text { memanfaatkan potensi } \\
\text { sumber daya perikanan yang } \\
\text { besar melalui program } \\
\text { pemerintah yang mendukung } \\
\text { pengembangan usaha } \\
\text { penangkapan ikan ( } \mathrm{S} 1, \mathrm{~S} 2 \text {, } \\
\text { O3, O4) } \\
\text { 2. Meningkatkan usaha } \\
\text { penangkapan ikan dengan } \\
\text { memanfaatkan pengalaman } \\
\text { baik yang dimiliki nelayan } \\
\text { pada lokasi penangkapan } \\
\text { yang luas (S3, O1, O2) }\end{array}$ & $\begin{array}{l}\text { 1. Memanfaatkan program } \\
\text { pemerintah yang } \\
\text { mendukung pengembangan } \\
\text { usaha perikanan melalui } \\
\text { pelatihan SDM untuk } \\
\text { mengatasi pendidikan } \\
\text { nelayan yang rendah serta } \\
\text { keterampilan dan } \\
\text { penguasaan teknologi yang } \\
\text { masih kurang (W2, W1, } \\
\text { O4) } \\
\text { Memanfaatkan program } \\
\text { pemerintah untuk } \\
\text { mengatasi keterbatasan } \\
\text { modal, alat tangkap dan } \\
\text { armada penangkapan yang } \\
\text { dimiliki nelayan pada usaha } \\
\text { penangkapan ikan (W3, } \\
\text { W4, W5, O4) }\end{array}$ \\
\hline Ancaman (Threats-T) & Strategi S-T & Strategi W-T \\
\hline $\begin{array}{l}\text { 1. Kerusakan ekosistem laut } \\
\text { akibat penangkapan } \\
\text { destruktif (T1) } \\
\text { 2. Harga pasar ditentukan } \\
\text { oleh pihak pengumpul (T2) } \\
\text { 3. Harga BBM tinggi (T3) } \\
\text { 4. Hasil produksi berfluktuasi } \\
\text { (T4) } \\
\text { 5. Perbatasan di wilayah laut } \\
\text { (T5) }\end{array}$ & $\begin{array}{l}\text { 1. Melakukan inovasi } \\
\text { pengembangan produksi } \\
\text { perikanan yang bernilai } \\
\text { tambah dengan } \\
\text { memanfaatkan semangat } \\
\text { kerja nelayan untuk } \\
\text { menghindari dampak hasil } \\
\text { produksi perikanan yang } \\
\text { berfluktuasi ( } \mathrm{S} 1, \mathrm{~T} 4, \mathrm{~T} 5) \\
\text { 2. Memanfaatkan pengalaman } \\
\text { baik yang dimiliki nelayan } \\
\text { pada usaha penangkapan ikan } \\
\text { untuk menghindari kerusakan } \\
\text { ekosistem laut akibat } \\
\text { penangkapan destruktif (S3, } \\
\text { T1) }\end{array}$ & $\begin{array}{l}\text { 1. Meningkatkan pengetahuan } \\
\text { SDM serta pengembangan } \\
\text { keterampilan yang bernilai } \\
\text { tambah untuk menghindari } \\
\text { hasil produksi yang } \\
\text { berfluktuasi (W2, W1, T4) } \\
\text { 2. Meningkatkan modal } \\
\text { nelayan untuk menghindari } \\
\text { dampak dari kenaikan } \\
\text { harga BBM (W3, W6, T2, } \\
\text { T3) }\end{array}$ \\
\hline
\end{tabular}




\section{SIMPULAN}

1. Alat tangkap jaring insang memberikan kontribusi yang besar terhadap produksi perikanan Kabupaten Maluku Tenggara. Alat tangkap ini umumnya menggunakan perahu tanpa motor serta perahu motor tempel.

2. Hasil analisis matriks IFE menunjukkan faktor internal yang dominan sebagai pendukung yaitu semangat kerja nelayan tinggi. Faktor internal yang dominan sebagai penghambat yaitu tingkat pendidikan nelayan rendah. Hasil analisis matriks EFE menunjukkan faktor eksternal yang dominan sebagai pendukung yaitu potensi sumber daya perikanan tangkap besar dan faktor eksternal yang dominan sebagai penghambat yaitu hasil produksi berfluktuasi.

\section{DAFTAR PUSTAKA}

Bahari R. 1989. Peran Koperasi Perikanan dalam Pengembangan Perikanan Rakyat. Prosiding Temu Karya Ilmiah Perikanan Rakyat, Jakarta 18-19 Desember 1989. Pusat Penelitian dan Pengembangan Perikanan. Badan Penelitian dan Pengembangan Pertanian. Departemen Pertanian. Jakarta. Hlm 165-180.

Barus HR, Badrudin, Naamin. 1991. Proseding Forum II Perikanan. Sukabumi. 18-21 Juni 1991. Pusat Penelitian dan Pengembangan Pertanian. Departemen Pertanian. Jakarta. Hlm 165-180.

David FR. 2006. Manajemen Strategik (Terjemahan). Jakarta (ID): Salemba Empat.

[DKP] Dinas Kelautan dan Perikanan Kabupaten Maluku Tenggara. 2012. Buku Tahunan Statistik Perikanan Kabupaten Maluku Tenggara. (ID): DKP, Kabupaten Maluku Tenggara.

Hobday AJ. 2010. Esemble Analysis Of The Future Distribution Of Large Pelagic Fishes Off Australia. 86(2010):291-301. doi: 10.1016/j.pocean. 2010.04-023.

Martasuganda S. 2008. Teknologi Penangkapan Ikan Berwawasan Lingkungan. Bogor (ID): Institut Pertanian Bogor.

Solihin A. 2010. Politik Hukum Kelautan dan Perikanan. Bandung (ID): Nuansa Aulia. 